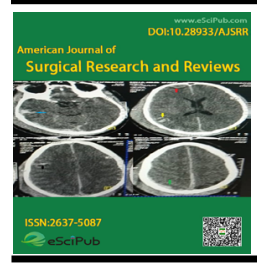

American Journal of Surgical Research and Reviews (ISSN:2637-5087)

\title{
Diagnostic Indexes Findings in Early Stages of Appendicitis (DIFESA Study): a reanalysis from the POSAW study database
}

Carlos Augusto Gomes ${ }^{1^{*}}$, Luis Pordeus Shafee ${ }^{1}$, Ana Luíza de Castro Carvalho', Lucas Machado de Souza Vicente ${ }^{2}$, Felipe Couto Gomes ${ }^{2}$, Mauro Podda ${ }^{3}$, Belinda de Simone ${ }^{4}$, Massimo Sartelli ${ }^{5}$, Fausto Catena ${ }^{6}$

${ }^{1}$ Department of Surgery, Hospital Universitário, Universidade Federal de Juiz de Fora. MG, Brasil. ${ }^{2}$ Hospital Universitário Terezinha de jesus, Faculdade de Ciências Médicas e da Saúde de Juiz de FORA, MG, Brasil. ${ }^{3}$ Department of Surgical Science University of Cagliari (Italy). ${ }^{4}$ Unit of Metabolic, Digestive and Emergency Surgery, Centre Hospitalier Intercommunal de Poissy et Saint Germain en Laye, France. ${ }^{5}$ General and Emergency Surgery, Macerata Hospital, Macerata, Italy. ${ }^{6}$ Bufalini Hospital Cesena Italy

\section{ABSTRACT}

Purpose: The resection of a normal-looking appendix during laparoscopic appendicectomy (LA) remains a dilemma. The optimal approach requires reliable macroscopic judgment by the surgeons. The aim of this study is to assess the surgeon's ability to laparoscopically diagnose acute appendicitis (AA) in its initial uncomplicated grades. Method: Subgroup analysis from the POSAW study, 2016. Patients diagnosed with initial grades of AA $(0$ - 1) who underwent LA were included $(n=718)$. The median age was 29.4 years, and $52 \%$ were female. The accuracy of the macroscopic intraoperative diagnosis was assessed with the histopathological examination of the resected specimens, and the agreement between the surgeon's and the pathologist's judgment was established. Results: Of the 79 appendices classified intraoperatively as normal-looking, 18 (22.8\%) had some inflammation degree. Of the 639 appendices classified intraoperatively as inflamed, 101 (15.8\%) were normal. The intraoperative surgeon's judgment had an accuracy of $83.4 \%$ and a moderate to low agreement (Kappa 0.42). The sensitivity and specificity values were $96.8 \%$ and $37.7 \%$, and the positive and negative predictive values were $84.2 \%$ and $77.2 \%$, respectively. Conclusion: The surgeon's intraoperative diagnosis of uncomplicated AA's initial grades is not sufficiently accurate to establish good reliability for appendicectomy. The surgeon overestimates the presence of appendicular inflammation.

Keywords: Appendicitis; Appendectomy; Laparoscopy, Diagnosis.

*Correspondence to Author: Carlos Augusto Gomes

Department of Surgery, Hospital Universitário, Universidade Federal de Juiz de Fora. MG, Brasil.

How to cite this article:

Carlos Augusto Gomes, Luis Pordeus Shafee, Ana Luíza de Castro Carvalho, Lucas Machado de Souza Vicente, Felipe Couto Gomes, Mauro Podda, Belinda de Simone Massimo Sartelli, Fausto Catena. Diagnostic Indexes Findings in Early Stages of Appendicitis (DIFESA Study): a reanalysis from the POSAW study database. American Journal of Surgical Research and Reviews, 2021, 4:35

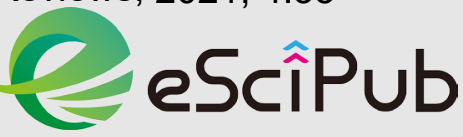

eSciPub LLC, Houston, TX USA. Website: https://escipub.com/ By using the site/services, you are agreeing to our Policies: https:// escipub.com/terms-privacy-policydisclaimer/ 


\section{INTRODUCTION}

Acute appendicitis (AA) is among the most common causes of acute abdominal pain. It is one of the main indications for emergency surgery globally, with a global incidence ranging from 100 to 151 cases per 100,000 inhabitants per year ${ }^{[1]}$. The lifetime risk of developing $A A$ is estimated to be $8.6 \%$ to $12 \%$ in men and $6.7 \%$ to $23.1 \%$ in women, with a peak incidence from 10 to 19 years of age ${ }^{[2]}$. AA can be stratified into complicated or uncomplicated, with complications being defined by the presence of necrosis, perforation, or abscess, which significantly increase mortality rates ${ }^{[3,4]}$.

The diagnosis and preoperative stratification of AA can be challenging, as they involve a critical analysis of a set of clinical, laboratory, and imaging findings. Even with the advances observed in imaging techniques, neither Magnetic Resonance (MRI) nor Computed Tomography (CT) can differentiate complicated and uncomplicated $A A^{[5,6]}$, which results in a late diagnosis, usually inside the operating room.

Appendectomy has historically been the treatment of choice for AA, with the laparoscopic approach currently being advocated for having the highest success rates and the lowest rates of complications, the shortest hospital stay, and overall best quality of life ${ }^{[6-10]}$. The intraoperative visualization of the appendix's signs of inflammation is seen as the main factor in deciding between performing the appendicectomy or leaving the appendix in situ [11]. Studies point to a moderate diagnostic accuracy of the surgeon when graduating $A A$, being lower for uncomplicated cases ${ }^{[12-14]}$. This can mean low reliability in the intraoperative differentiation between a normal appendix and an inflamed appendix. Thus, whether the macroscopically normal appendix should be removed remains a dilemma in the literature.

This study aims to evaluate, from a multicenter perspective, the surgeon's ability to laparoscopically diagnose AA in its initial uncomplicated forms, in order to quantify the basis of the decision-making regarding the intraoperative diagnosis and the subsequent therapeutic strategy.

\section{MATERIAL AND METHODS Study Design}

This study is a post-hoc analysis of the Prospective Observational Study on acute Appendicitis Worldwide (POSAW) at 116 medical centers in 44 countries over six months ${ }^{[15]}$. During this period, all patients admitted with a diagnosis of AA were sequentially studied and followed up until hospital discharge or transfer to another hospital, with a total of 4,284 patients recruited. The service protocols and the conducts adopted by each institution were preserved. The data were compiled by the coordinators of each institution and monitored by a coordination center. The study was approved and supervised by the World Society of Emergency Surgery (WSES) and strictly followed all ethical guidelines.

\section{Ethics Declaration}

As this is an observational study, the ethics committee's approval was not required to analyze the data to develop the POSAW study. The WSES was responsible for the study protocol's direction and approval, which guarantees good ethical conduct. The data used for analysis were used anonymously, and the risks of the research were minimal.

\section{Patient Eligibility}

Inclusion criteria were patients of any gender or age diagnosed with AA who underwent laparoscopic appendicectomy. In order to analyze the disease in its initial forms, the exclusion criteria were patients who were in more advanced AJSRR: https://escipub.com/american-journal-of-surgical-research-and-reviews/ 
stages of the disease, thus excluding those who presented complicated forms of AA (such as suppuration, phlegmon, abscess, necrosis, or perforation) observed by the surgeon or at the final histopathology. Only those with all the variables delimited to the study were considered. Patients treated with open surgery or appendectomies performed during other surgical procedures were omitted.

\section{Studied Variables}

The demographic variables studied were patients' sex and age. The variable chosen for diagnostic accuracy analysis was the laparoscopic classification proposed by Gomes et al. and recommended by the WSES ${ }^{[16]}$. This classification is based on clinical, imaging, and laparoscopic findings to delimit the evolution of AA into five degrees: $0=$ normal-looking appendix (endoappendicitis or periapendicitis), 1 = inflamed appendix (hyperemia, edema, fibrin, with or little pericolic fluid), 2 = necrosis ( $A$ : segmental necrosis / $B$ : necrosis of the base), 3 = inflammatory tumor (A: phlegm, B: abscess less than 5 $\mathrm{cm}$ without peritoneal air, C: abscess greater than $5 \mathrm{~cm}$ without peritoneal free air ), $4=$ perforated (diffuse peritonitis, with or without peritoneal free air) (TABLE 1).

Table 1: Clinical, imaging, and laparoscopic classification of acute appendicitis

\begin{abstract}
Non Complicated Acute Appendicitis
Grade 0 - Normal-looking Appendix ( Endoappendicitis or sublocalized Periapendicitis )

Grade 1 - Inflamed Appendix: Hyperemia, edema \pm Fibrin with or without a small amount of pericolic fluid

\section{Complicated Acute Appendicitis}

Grade 2 - Necrosis

Grade 3 - Inflammatory Tumor

\section{A - Segmental Necrosis (with or without a small amount of pericolic fluid) \\ B - Base necrosis (with or without a small amount of pericolic fluid )}

$$
\begin{aligned}
& \text { A- Phlegm } \\
& \text { B - Abscess < } 5 \mathrm{~cm} \text { (without pneumoperitoneum) } \\
& \text { C - Abscess }>5 \mathrm{~cm} \text { (without pneumoperitoneum) }
\end{aligned}
$$

Grade 4 - Perforated: diffuse peritonitis with or without pneumoperitoneum

Gomes et al. (2015)

The histopathological result was used as the gold standard for diagnosing AA, defined by transmural inflammation of the appendix and neutrophilic invasion of the muscle layer ${ }^{[17]}$. Histopathological evaluation makes it possible to differentiate between periapendicitis (invasion restricted to serous and subserous, without affecting the mucosa) and endoappendicitis (invasion of the mucosa and ulceration) ${ }^{[18,19] .}$ This examination is recommended in all appendectomies ${ }^{[4,20]}$

Therefore, only uncomplicated initial forms of AA were included for this study, with only patients with grade 0 or 1 by Gomes et al. and those with histological results showing a normal appendix, periapendicitis endoappendicitis, or 
inflammation. Complicated cases, such as intraoperative grades $2 \mathrm{~A}, 2 \mathrm{~B}, 3 \mathrm{~A}, 3 \mathrm{~B}, 3 \mathrm{C}$, or 4 and histopathological results that denote suppuration, gangrene, or perforation, were excluded from the analysis.

\section{Statistical Analysis}

The data were organized and analyzed using the OpenEpi version 3.0 program. A 95\% Confidence Interval $(\mathrm{Cl})$ was established, with $\mathrm{p}$-values below 0.05 being considered significant. A $2 \times 2$ contingency table was used as a diagnostic test to calculate sensitivity, specificity, positive predictive value, negative predictive value, and accuracy. The unweighted Kappa coefficient and the percentage of the agreement were used to define the degree of interobserver agreement between the laparoscopic classification and the histopathological results according to the criteria of Landis and Koch [21]: low or at random $(<0.00)$, light $(0.0-0.2)$, reasonable (0.21-0.4), moderate (0.41 - 0.6), significant (0.61 - 0.8) and excellent or almost perfect $(0.81$ - 1.0). McHugh's interpretation [22] for Kappa values was also considered and is based on the percentage of reliable data in the sample: none $(0.0-0.2)$, minimum (0.21$0.4)$, low (0.41 - 0.6), moderate (0.61 - 0.8), strong $(0.81-0.9)$ and almost perfect $(>0.9)$.

\section{RESULTS}

\section{Demographic Analysis $(n=718)$}

A total of 718 patients were included in the study. Regarding the demographic distribution, 372 $(51.8 \%)$ patients were female and 346 (48.2\%) male. The mean age was 29.4 years, and the median age was 26 years.

\section{Anatomopathological study of the resected specimens}

The anatomopathological result showed that $556(77.4 \%)$ appendices were inflamed, 89 $(12.4 \%)$ were normal, and $73(10.2 \%)$ had periapendicitis. No cases of endoappendicitis were reported.

\section{Surgeon's macroscopic evaluation during the appendectomy}

In the laparoscopic macroscopic evaluation, 79 (11\%) patients were classified with AA grade 0 , and 639 (89\%) were classified as grade 1 . Of the appendices classified as grade 0 , the histopathological study revealed inflammation in 18 $(22.8 \%)$. Of the appendices classified as grade 1 , the histopathological study revealed normality in $35(5.5 \%)$ and periapendicitis in 66 (10.3\%). Results are summarized in Table 2.

Table 2: Result of the comparison between the laparoscopic classification ${ }^{* 1}$ and the histopathological study in patients undergoing laparoscopic appendectomy.

\begin{tabular}{|c|c|c|c|}
\hline \multirow{2}{*}{$\begin{array}{l}\text { Surgeons Macroscopic Classification } \\
\qquad(n=718)\end{array}$} & \multicolumn{3}{|c|}{ Histopathological Study $(n=718)$} \\
\hline & Inflamed (\%) & Normal $* 2(\%)$ & Total (\%) \\
\hline Grade 1 & $538(74.9)$ & $101(14.1)$ & $639(89)$ \\
\hline Grade 0 & $18(2.5)$ & $61(8.5)$ & $79(11)$ \\
\hline Total & $556(77.4)$ & $162(22.6)$ & $718(100)$ \\
\hline
\end{tabular}

\footnotetext{
${ }^{* 1}$ Gomes CA, Sartelli M, Di Saverio S, et al. Acute appendicitis: proposal of a new comprehensive grading system based on clinical, imaging, and laparoscopic findings. World J Emerg Surg. 2015; 10:60. *2 Normal: includes normal appendices and periapendicitis. No cases of endoappendicitis have been reported.
} 
Results of the interobserver agreement analysis: percentage of agreement and Kappa coefficient

In the histologically inflamed appendices group, there was an agreement with the surgeon in 538 out of 556 cases (Percentage of agreement $96.8 \%)$. There was agreement in the group of pathology-free appendices in the histopathological study in 54 of 89 cases (Percentage of agreement $60.7 \%$ ). In the group of appendices with periapendicitis in the histopathological study, there was agreement in 7 of 73 cases (Percentage of agreement $9.6 \%$ ). The overall disagree- ment rate was $16.6 \%$, and the Kappa confficient of the agreement was 0.42 (95\% Cl: $0.35-0.49)$. Result of calculations of laparoscopic diagnostic indexes in initial forms of AA: sensitivity, specificity, and predictive values

Five hundred ninety-nine patients were correctly diagnosed by the surgeon, which resulted in an accuracy of $83.4 \%$. The sensitivity and specificity values were $96.8 \%$ and $37.7 \%$, while the positive and negative predictive values were $84.2 \%$ and $77.2 \%$, respectively. The results and their corresponding confidence intervals are reported in Table 3.

Table 3: Sensitivity, specificity, accuracy and predictive values of laparoscopy in early forms of Acute Appendicitis

\begin{tabular}{ccc}
\hline Índex & Calculation (\%) & CI 95\% \\
\hline Sensitivity & 96.76 & $94.9-97.9$ \\
Specificity & 37.7 & $30.6-45.3$ \\
Accuracy & 83.4 & $80.5-86$ \\
Positive Predictive Value & 84.2 & $81.2-86.8$ \\
Negative Predictive Value & 77.2 & $66.8-85$ \\
Cohen's Kappa & 0.42 & $0.35-0.49$ \\
\hline
\end{tabular}

\section{DISCUSSION}

The management of the visually normal appendix during laparoscopy is considered a dilemma in the literature due to conflicting arguments both for and against its removal and the lack of recommendations with a high level of evidence. The decision between removing the normal appendix or leaving it in situ must analyze the risks and benefits of appendectomy, the individual clinic of each patient, and the surgeon's diagnostic accuracy [4, 23]. The intraoperative visualization of signs of inflammation of the appendix is seen as the main factor in the decision to perform the appendectomy [11], and the graduation of complications is critical to define the procedures regarding complicated and uncomplicated cases, the prolongation of antibiotic therapy and the surgical technique employed.

In this study, it was observed that the surgeon does not have good accuracy in the diagnosis of uncomplicated forms of AA, with an accuracy value of only $83.4 \%$ and sensitivity and 
specificity values of $96.8 \%$ and $37.7 \%$, respectively. The predictive values were found to show a rate of $84.2 \%$ for appendices classified as inflamed and $77.2 \%$ for appendices classified as normal. This demonstrates a low diagnostic threshold in macroscopic criteria used during surgery, which often overestimate the presence of appendicular inflammation. These data corroborate with other studies that point out that the surgeon's intraoperative diagnosis is not reliable to predict abnormalities of the appendix [24, 25]. Furthermore, analyzing the agreement rates between the macroscopic and histological classification, we observed a higher rate of agreement in the group of histologically inflamed appendices $(96.8 \%)$, lower rates in the histologically normal group $(60.7 \%)$, and the lowest in the group with periapendicitis, with only $9.6 \%$ agreement. This resulted in an interobserver agreement rate considered moderate to low by the adopted criteria (Kappa 0.42 - 95\% Cl: 0.35 0.49). Studies show that this agreement rate between the surgeon and the pathologist has considerable variability $[26,27]$. The study conducted by Strong et al. obtained a more significant agreement (Kappa 0.57) when including complicated forms of $A A$ in his analysis, which may demonstrate a greater difficulty in classifying the initial forms of the disease ${ }^{[13]}$. Another study by Van Den Boom et al. assessed the intraoperative classification agreement among surgeons with varying degrees of experience and observed a high rate of disagreement among these evaluators ${ }^{[14]}$.

The rate of negative appendectomy, defined as removing a histologically normal appendix without intramural neutrophilic invasion, was $22.6 \%$ in this study. These rates can vary from $6-8 \%$ to $17-36 \%$ in some centers ${ }^{[28,29]}$. There has been a decrease in negative appendectomy rates over the years. The prospective analysis of the database with 7964 patients from the Swiss Association of Laparoscopic and Thoracoscopic Surgery demonstrated a reduction in the number of negative appendectomies: from $12.7 \%$ in 1995 to $2.8 \%$ in 2006 [30]. The observed rates' significant variability was related to preoperative factors, such as the routine use of clinical scores and imaging methods. The Alvarado score was able to reduce these rates to $<8 \%$ and, associated with CT, managed to reduce it to $3.3 \%{ }^{[28]}$. Besides, female gender, younger age group, absence of peritonitis, pain lasting less than 24 hours, pain with migratory nature, altered white blood cell count, and fever were identified as positive predictors of negative appendectomy [31, 32]. Another study showed that these rates were considerably higher in females than males $(31.0 \% \text { vs. } 16.8 \%)^{[33]}$. Some suggest that CT scan should not be performed routinely due to the risk of false negatives ${ }^{[28]}$. However, it can be considered in cases of diagnostic doubt, female patients of childbearing age and patients with a high risk of atypical presentations ${ }^{[34]}$.

Removing a normal appendix is not risk-free, and some recent studies show that it has similar rates of complications compared to appendectomy of inflamed appendices [35 - 38]. In a recent cohort study with 1413 patients, no significant differences were found in the rates of morbidity between negative appendectomy and uncomplicated appendectomy (6.3\% vs. $6.9 \% ; P=0.48)$, which evidences the need to improve the selection criteria of patients who must undergo the procedure ${ }^{[31]}$. Another relevant point is the loss of the organ's immune function and the storage of bacteria, capable of restoring the intestinal microbiota in dysbiosis situations [39]. Thus, some studies advocate preserving the normal appendix during diagnostic laparoscopy if there are no -journal-of-surgical-research-and-reviews/ 
signs of other pathologies that justify the pa-

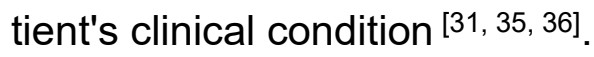

On the other hand, the risk of leaving an abnormal appendix must be balanced against the risks related to surgery. Also, it is worth mentioning that the surgeon's intraoperative judgment does not improve over time, and the degree of experience does not increase intraoperative accuracy $[12,13,40]$. The World Society of Emergency Surgery (WSES) and the European Association of Endoscopic Surgery (EAES) recommend removing a macroscopically normal appendix in the absence of other intra-abdominal procedures due to the high chance of recurrence, persistence of symptoms, or possibility of sub localized malignancy.

As limitations of this study, we can mention the absence of analysis of ultrasound and computed tomography patterns, which may correlate with negative appendectomy rates and the absence of reported cases of endoappendicitis.

\section{REFERENCES}

[1] Ferris M, Quan S, Kaplan BS, et al. The Global Incidence of Appendicitis: A Systematic Review of Population-based Studies. Ann Surg. 2017;266(2):237241.

https://doi.org/10.1097/sla.0000000000002188

[2] Wagner M, Tubre DJ, Asensio JA. Evolution and Current Trends in the Management of Acute Appendicitis. Surg Clin North Am. 2018;98(5):1005-1023. https://doi.org/10.1016/j.suc.2018.05.006

[3] Bhangu A, Søreide K, Di Saverio S, Assarsson JH, Drake FT. Acute appendicitis: modern understanding of pathogenesis, diagnosis, and management. Lancet. 2015 Sep 26;386(10000):1278-1287. doi: 10.1016/S0140-6736(15)00275-5. Erratum in: Lancet. 2017 Oct 14;390(10104):1736. PMID: 26460662. https://doi.org/10.1016/s0140-6736(15)00275-5

[4] Di Saverio S, Podda M, De Simone B, et al. diagnosis and treatment of acute appendicitis: 2020 update of the WSES Jerusalem guidelines. World $\mathrm{J}$ Emerg Surg. 2020;15(1):27. Published 2020 Apr 15. https://doi.org/10.1186/s13017-020-00306-3

[5] Leeuwenburgh MM, Wiezer MJ, Wiarda BM, Bouma WH, Phoa SS, Stockmann HB, Jensch S, Bossuyt PM, Boermeester MA, Stoker J; OPTIMAP study group. Accuracy of MRI compared with ultrasound imaging and selective use of CT to discriminate simple from perforated appendicitis. Br J Surg. 2014 Jan;101(1):e147-55.

https://doi.org/10.1002/bjs.9350

[6] Podda M, Andersson R, Boermeester M, Coccolini F, Sartelli M, Moore EE, Sugrue M, Abu-Zidan F, ToIonen M, Damaskos D, Kluger Y, Soreide K, Pisanu A, Augustin G, Latifi R, Kelly M, Leppaniemi A, Fraga GP, Ten Broek R, Tan E, Van Goor H, Chiara O, Maier RV, Pata F, De Simone B, Ordoñez CA, Ansaloni L, Catena F, Di Saverio S. Do young patients with high clinical suspicion of appendicitis really need cross sectional imaging? Proceedings from a highly controversial debate among the experts' panel of 2020 WSES Jerusalem Guidelines. J Trauma Acute Care Surg. 2021 Jan 25. https://doi.org/10.1097/ta.0000000000003097

[7] Poillucci G, Mortola L, Podda M, et al. Laparoscopic appendectomy vs antibiotic therapy for acute appendicitis: a propensity score-matched analysis from a multicenter cohort study. Updates Surg. 2017;69(4):531-540. https://doi.org/10.1007/s13304-017-0499-8

[8] Gomes CA, Sartelli M, Podda M, et al. Laparoscopic versus open approach for diffuse peritonitis from appendicitis ethiology: a subgroup analysis from the Physiological parameters for Prognosis in Abdominal Sepsis (PIPAS) study. Updates Surg. 2020;72(1): 185-191. https://doi.org/10.1007/s13304-02000711-y

[9] Jaschinski T, Mosch C, Eikermann M, Neugebauer EA. Laparoscopic versus open appendectomy in patients with suspected appendicitis: a systematic 
review of meta-analyses of randomised controlled trials. BMC Gastroenterol. 2015;15:48. Published 2015 Apr 15. https://doi.org/10.1186/s12876-0150277-3

[10] Podda M, Gerardi C, Cillara N, Fearnhead N, Gomes CA, Birindelli A, Mulliri A, Davies RJ, Di Saverio S. Antibiotic Treatment and Appendectomy for Uncomplicated Acute Appendicitis in Adults and Children: A Systematic Review and Meta-analysis. Ann Surg. 2019 Dec;270(6):1028-1040. PMID: 30720508. https://doi.org/10.1097/sla.0000000000003225

[11] Slotboom T, Hamminga JT, Hofker HS, Heineman E, Haveman JW; Apple Study Group Appendicitis and Laparoscopic Evaluation. Intraoperative motive for performing a laparoscopic appendectomy on a postoperative histological proven normal appendix. Scand J Surg. 2014;103(4):245-248. https://doi.org/10.1177/1457496913519771

[12] Thong DW, Crouch S, Morgan S, Arthur T; QUEST Collaboration. Can Surgeons Identify Appendicitis Macroscopically? Results From a Multicentre Prospective Study. SurgLaparoscEndoscPercutan Tech. 2019 Oct;29(5):344-348. https://doi.org/10.1097/sle.0000000000000687

[13] Strong S, Blencowe N, Bhangu A. How good are surgeons at identifying appendicitis? Results from a multicentre cohort study. Int J Surg. 2015;15:107-12. https://doi.org/10.1016/j.ijsu.2015.01.032

[14] Van den Boom AL, de Wijkerslooth EML, Mauff KAL, et al. Interobserver variability in the classification of appendicitis during laparoscopy: Interobserver variability in classification of appendicitis during laparoscopy. $\mathrm{Br}$ J Surg. 2018;105:1014-9. https://doi.org/10.1002/bjs.10837

[15] Sartelli M, Baiocchi GL, Di Saverio S, et al. Prospective Observational Study on acute Appendicitis Worldwide (POSAW). World J EmergSurg. 2018;13:19. https://doi.org/10.1186/s13017-0180179-0
[16] Gomes CA, Sartelli M, Di Saverio S, et al. Acute appendicitis: proposal of a new comprehensive grading system based on clinical, imaging and laparoscopic findings. World J Emerg Surg. 2015;10:60. https://doi.org/10.1186/s13017-015-0053-2

[17] Gorter RR, Eker HH, Gorter-Stam MA, et al. diagnosis and management of acute appendicitis. EAES consensus development conference 2015. SurgEndosc. 2016; 30(11): 4668-4690. https://doi.org/10.1007/s00464-016-5245-7

[18] Chaudhary P, Nabi I, Arora MP. Periappendicitis: our 13 year experience. Int J Surg. 2014;12(9):1010-3. https://doi.org/10.1016/j.ijsu.2014.07.265

[19] Carr NJ. The pathology of acute appendicitis. Ann DiagnPathol. 2000;4(1):46-58. https://doi.org/10.1016/s1092-9134(00)90011-x

[20] Bastiaenen VP, Allema WM, Klaver CEL, et al. Routine histopathologic examination of the appendix after appendectomy for presumed appendicitis: Is it really necessary? A systematic review and meta-analysis. Surgery. 2020;168(2):305-312.

https://doi.org/10.1016/i.surg.2020.03.032

[21] Landis RJ, Koch GG. The measurement of observer agreement for categorical data. Biometrics. 1977;33:159-174. PMID: 843571

[22] McHugh ML. Interrater reliability: the kappa statistic. Biochem Med (Zagreb). 2012;22(3):276-82. PMID: 23092060

[23] Zosimas D, Lykoudis PM, Burke J, Strano G, Leung P, Shatkar V. Postoperative outcomes in laparoscopic appendicectomies with histopathologically normal appendix. Ann Ital Chir. 2019;90:72-77. PMID: 30467271

[24] Šuta Kimle K, Chrz K, Ulrych J, Šimůnková E, Michalský D. Congruence of histological diagnosis with imaging and operation diagnosis in acute appendicitis. RozhlChir. 2019 Winter;98(11):457-461. https://doi.org/10.33699/pis.2019.98.11.457461 
[25] Jones AE, Phillips AW, Jarvis JR, Sargen K (2007) The value of routine histopathological examination of appendicectomy specimens. BMC Surg 7(1):17. https://doi.org/10.1186/1471-2482-7-17

[26] Cho J, Lee D, Sung K, Baek J, Lee J. Clinical implication of discrepancies between surgical and pathologic diagnoses of acute appendicitis. Ann Surg Treat Res. 2017; 93(1): 43-49. https://doi.org/10.4174/astr.2017.93.1.43

[27] Correa J, Jimeno J, Vallverdu H, et al. Correlation between intraoperative surgical diagnosis of complicated acute appendicitis and the pathology report: clinical implications. Surg Infect (Larchmt). 2015;16(1):41-44.

https://doi.org/10.1089/sur.2013.155

[28] Mariadason JG, Wang WN, Wallack MK, Belmonte A, Matari $\mathrm{H}$. Negative appendicectomy rate as a quality metric in the management of appendicitis: impact of computed tomography, Alvarado score and the definition of negative appendicectomy. Ann R Coll Surg Engl. 2012 Sep;94(6):395-401. https://doi.org/10.1308/003588412×1317122159213

[29] Bhangu A; RIFT Study Group on behalf of the West Midlands Research Collaborative. Evaluation of appendicitis risk prediction models in adults with suspected appendicitis. Br J Surg. 2020 Jan;107(1):7386. doi: 10.1002/bjs.11440. Epub 2019 Dec 3. PMID: 31797357;

PMCID:

PMC6972511.

https://doi.org/10.1002/bjs.11440

[30] Charfi S, Sellami A, Affes A, Yaïch K, Mzali R, Boudawara TS. Histopathological findings in appendectomy specimens: a study of 24,697 cases. Int J Colorectal Dis. 2014 Aug;29(8):1009-12. https://doi.org/10.1007/s00384-014-1934-7

[31] Allaway MGR, Eslick GD, Cox MR. The Unacceptable Morbidity of Negative Laparoscopic Appendicectomy. World J Surg. 2019 Feb; 43(2): 405-414. https://doi.org/10.1007/s00268-018-4784-6

[32] Güller U, Rosella L, McCall J, Brügger LE, Candinas D. Negative appendicectomy and perforation rates in patients undergoing laparoscopic surgery for suspected appendicitis. Br J Surg. 2011 Apr;98(4):58995. https://doi.org/10.1002/bjs.7395

[33] Chandrasegaram MD, Rothwell LA, An El, Miller RJ. Pathologies of the appendix: a 10-year review of 4670 appendicectomy specimens. ANZ J Surg. 2012 Nov; 82(11): 844-7. https://doi.org/10.1111/j.14452197.2012.06185.x

[34] Sarr MG. CT scan in complicated appendicitis diagnosis: a very costly option. Dig LiverDis. 2004 Mar;36(3):174.

https://doi.org/10.1016/j.dld.2003.12.007

[35] Lee M, Paavana T, Mazari F, Wilson TR (2014). The morbidity of negative apendicectomy. Ann R Coll SurgEngl $\quad 96 \quad$ (7): https://doi.org/10.1308/003588414x139461849 03801

[36] Sørensen AK, Bang-Nielsen A, Levic-Souzani K, et al. Readmission and reoperation rates following negative diagnostic laparoscopy for clinically suspected appendicitis: The "normal" appendix should not be removed - A retrospective cohort study [published correction appears in Int J Surg. 2020 Jul;79:154]. Int J Surg. 2019;64:1-4.

https://doi.org/10.1016/j.jjsu.2020.05.053

[37] Bijnen CL, Van Den Broek WT, Bijnen AB, De Ruiter $\mathrm{P}$, Gouma DJ. Implications of removing a normal appendix. Dig Surg. 2003;20(2):115-21. PMID: 12686778. https://doi.org/10.1159/000069386

[38] Das MK, Gautam D, Roy H, Mukherjee A, Gaurav R, Sen S. Unnecessary appendicectomy in suspected cases of acute appendicitis. J Indian Med Assoc. 20 09 Jun;107(6):354, 356-7. PMID: 19886373.

[39] Vitetta L, Chen J, Clarke S. The vermiform appendix: an immunological organ sustaining a microbiome inoculum. Clin Sci (Lond). 2019 Jan 3;133(1):1-8. https://doi.org/10.1042/cs20180956

[40] Pham H, Devadas M, Howle J. Effect of surgical experience on the macroscopic diagnosis of AJSRR: https://escipub.com/american-journal-of-surgical-research-and-reviews/ 
appendicitis: a retrospective cohort study. Int J Surg.

https://doi.org/10.1016/j.ijsu.2015.02.019

2015 Apr;16(Pt A):78-82.

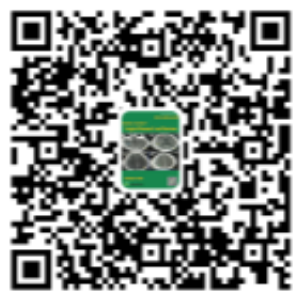

